\title{
Research on Development Strategies for Remanufacturing of China's Oil and Gas Pipelines
}

\author{
The Research Group for the Research on China's Development Strategy for Oil and Gas Pipeline Remanufacturing
}

\begin{abstract}
Oil and gas pipeline materials are an important means of prospecting, exploiting, and transporting oil and gas; however, they are largely abandoned due to tubing failure caused by corrosion, wear and tear, and scaling. Pipeline materials are piling up in oil fields, causing an enormous waste of resources, as well as environmental pollution. In this study, we analyze the treatment status and existing problems of oil and gas pipeline materials waste. Using advanced remanufacturing technology, we demonstrate the economic, social, and environmental benefits of remanufacturing pipeline materials. In addition, we suggest an industrial mode for remanufacturing China's oil and gas pipeline materials. Furthermore, we propose development methods for promoting independent innovation. We present a novel concept and technology that will decrease the costs and increase the benefits for China's oil and gas industry, thus leading to energy conservation and emission reduction, and promoting the construction of a circular economy in the oil and gas industry.
\end{abstract}

Keywords: oil; gas; pipeline; remanufacturing

Oil and gas are widely used as basic energy sources in every field of human life, thus becoming the prime promoting factors for development of social productivity. With many new oil wells entering the production in the oil industry, an upward trend in pipeline usage is observed every year. The 15 domestic oil fields owned by the China National Petroleum Corporation (CNPC) account for approximately $4.4 \times 10^{8} \mathrm{~m}$ downhole tubings, which is approximately $4 \times 10^{6} \mathrm{t}$ in weight. The 12 major oil fields owned by the China Petrochemical Corporation (SINOPEC) account for approximately $2.2 \times 10^{8} \mathrm{~m}$ downhole tubings weighing about $2 \times 10^{6} \mathrm{t}[1]$.

\section{Scrap and maintenance status and existing problems of domestic oil and gas pipelines}

\subsection{Scrap status of oil and gas pipelines}

$\mathrm{H}_{2} \mathrm{~S}, \mathrm{CO}_{2}$ contained in oil and gas, soil salinization degree, groundwater mineralization, and chlorine ion content can all lead to internal and external corrosion of pipelines. In addition, as waterflood recovery is widely used in oil wells, moisture content gradually increases every year with the increase of exploitation age limit. Water content rates of some old well even increase to over $80 \%$. Thus, pipelines corrode, perforate, leak, and burst, thereby causing large damage to the security of oil and gas production and the surrounding environment. According to statistics, about $7 \times 10^{5} \mathrm{t}$ domestic oil pipelines are scrapped per year [1].

\subsection{Maintenance status of oil and gas pipelines}

The conventional processing technique is still used for pipeline recovery. Considering an oil pipeline as an example, the general maintenance process is as follows: separation-cleaningstraightening-flaw detection-threading-coupling-pressure testdiameter drifting. As is shown in Fig. 1, the conventional tubing maintenance process is only the separation process of an old tubing. Defects caused by corrosion and wear and tear are not

Received date: April 25, 2017; Revised date: May 19, 2017

Corresponding author: Guo Lei. E-mail: jordon230@163.com

Funding program: CAE Advisory Project "Research on China's Development Strategy for Oil and Gas Pipeline Remanufacturing” (2015-XY-28).

Chinese version: Strategic Study of CAE 2017, 19 (3): 066-071

Cited item: The Research Group for the Research on China's Development Strategy for Oil and Gas Pipeline Remanufacturing. Research on Development Strategies for Remanufacturing of China's Oil and Gas Pipelines. Strategic Study of CAE, https://doi.org/10.15302/J-SSCAE-2017.03.010 


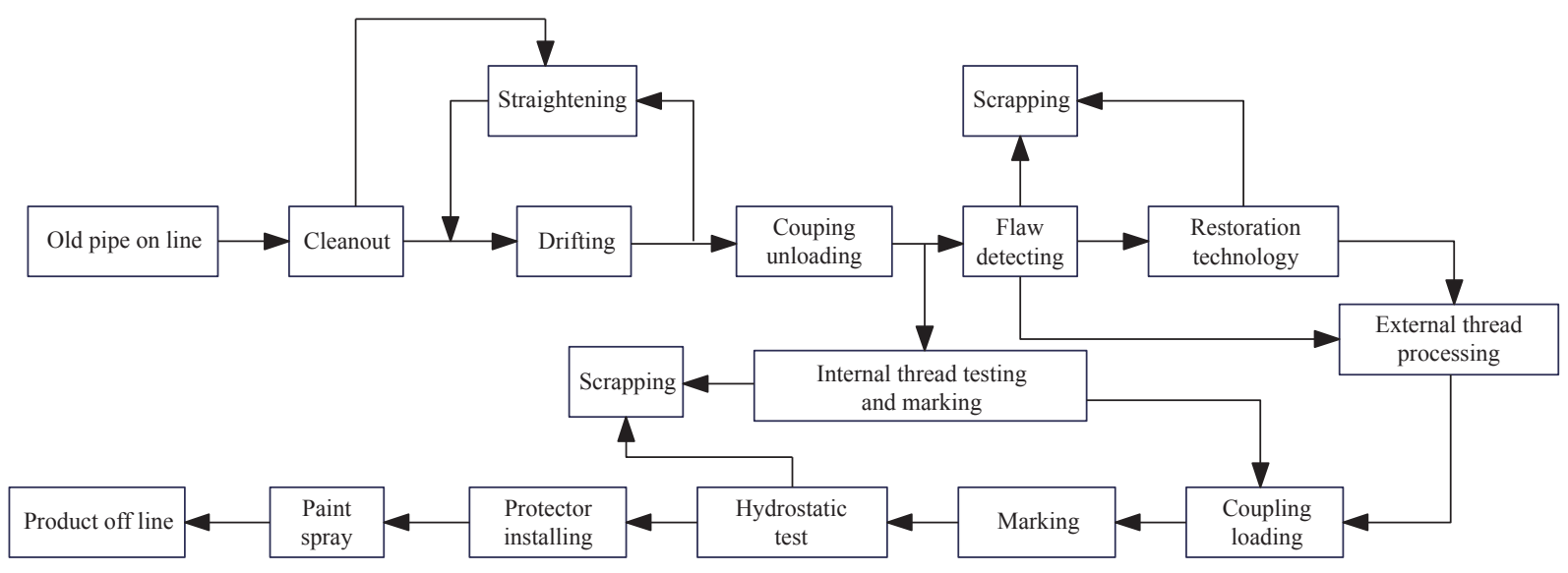

Fig. 1. Conventional processing flow of oil pipes.

radically recovered. However, a few oil pipelines can be maintained using simple repairing techniques; however, the repair rate is limited. During preliminary selecting, inspecting, pressure testing, and drifting, tubing scrap occurs frequently, resulting in waste of manpower, materials, and financial resources.

The conventional processing technique prefers simple processing of discarded pipes for performance improvement, for which the service life is its own residual life. Only a few pipes are used after degradation, whereas most of them are piled up as scrapped materials on yards, only existing as a figure on asset accounts, completely losing their values and resulting in waste.

\subsection{Existing problems of domestic oil and gas pipelines in reclamation}

A few scientific and reasonable solutions aim at these discarded pipes. Degradation and melting increases resource waste and environmental pollution.

\subsubsection{Idea lag}

Since long, due to the lack of clear positioning, demand, and development attitude toward pipeline reclamation in oil and gas industrial structure, relevant departments have not conducted adequate studies on sustainable development demand when formulating plans. Some policies and regulations set up barriers on the development of pipe objectively. In the meantime, the conditions of each field are different. Each department or institution varies in the cognition degree of pipe reclamation. The awareness of the significance of oil and gas industry development in China is still absent.

\subsubsection{Technical bottleneck}

Each field that has been inattentive to and not conducted special research on the treatment technology is responsible for the use and disposal of oil pipes. This has resulted in relatively simple maintenance techniques such as cleaning, straightening, inspection, and collar changing. Anti-corrosion, wear-resistant, fouling resistance, and pressure resistance performance are not improved. Thus, repaired pipes cannot satisfy the service standards, thus causing degradation.

\subsubsection{Environmental pollution}

The lack of effective management and scientific treatment exposes discarded pipes to the environment, which finally forms solid refuse and causes acute pollution of air, soil, and water quality. Some process such as acid and alkaline cleaning cause serious environmental pollution, with certain hidden security problems. In addition, the unreasonable cleaning and restoration also has a negative impact on the ecological environment

\section{Research on development strategies for remanufacturing of China's oil and gas pipelines}

In 2015, the Engineering Management Department of the Chinese Academy of Engineering (CAE) conducted a consulting project "Research on Chinese Development Strategy of Petroleum and Natural Gas Pipeline." With the joint efforts of six academicians and 50 experts for investigating several main oil and gas fields, such as Southwest, Tarim, Xinjiang, Tuha, Jilin, Jidong, and North, the definition, connotation, feature, system, key technology, and profits of oil and gas pipe remanufacturing were analyzed extensively. The research report on Chinese development strategy of petroleum and natural gas pipelines was then formed.

\subsection{Definition, connotation, and feature of remanufacturing}

\subsubsection{Definition of remanufacturing}

Remanufacturing is a general term for a series of technical measures or engineering activities that considers the product lifecycle theory as the guideline, focusing on better quality, high efficiency, energy saving, material saving, and environ- 
mental protection. Through advanced technology and industrialized production, it directs people to repair and remold old equipment $[2,3]$.

\subsubsection{Connotation and feature of remanufacturing}

Remanufacturing is a concept relative to manufacturing. Manufacturing is a process producing new, in which raw materials are transformed into applicable products to cater to the market. Remanufacturing is to improve the performance of discarded products through maintenance and upgrading for achieving better quality than the prototypes. Remanufacturing is a continuation of the manufacturing industry chain and an important component of green manufacturing. Relative to manufacturing that is based on original resources, remanufacturing requires less energy and resources while decreasing exhaust emission. An important characteristic of remanufacturing is that the quality and performance of remanufactured products are not lower than the new ones, while the cost is $50 \%$ lower. Meantime, $60 \%$ energy and $70 \%$ material can be saved The negative effects on the environment are significantly reduced $[2,3]$.

2.1.3 Independent innovation in the remanufacturing industrial model

Remanufacturing in the European countries and United States is developed based on the prototype manufacturing industry. The remanufacturing index proposed during the design stage is mainly based on "replacement repair" and "size repair" technically [1]. Replacement repair is to replace damaged parts by new parts integrally, whereas size repair is to reprocess the mismatched parts into fitted ones. However, this model requires heavy resource consumption and low remanufacturing rate.

Remanufacturing in China is based on maintenance and surface engineering. It mainly adopts the "size restoration" and "performance improving" methods, thus increasing the remanufacturing rate significantly and lowering the resource consumption, which has outstanding effects of energy conservation and emission reduction [3]

Since the end of the 20th century, China has initiated systematic research and practice on the basic theory and key technology of remanufacturing. At present, the remanufacturing industrial model with Chinese characteristics, based on advanced technology using size restoration and performance improving combined with production, study and research have been widely recognized at home and abroad, which is recycling and economic [2].

\subsection{Research on remanufacturing system of oil and gas pipelines}

As a burgeoning industry, the remanufacturing of oil and gas in China has preliminarily formed a recycling economic industry model that is centered on old part cleaning, testing and evalu- ation, key technology, and application, establishing a technical and management system of oil and gas pipe remanufacturing, as is shown in Fig. 2.

\subsection{Key and core technologies of oil and gas pipelines remanufacturing}

\subsubsection{Green cleaning technology}

With cleaning equipment and fluid, the grease, rust, dirt, carbon deposition, and other pollutants attached on the internal and external surfaces can be removed through mechanical, physical, chemical, and electrochemical methods to reach the required cleanliness. Commonly used cleaning techniques use heat, fluid, pressure, jet, bubble foam spray, high-pressure water jet, friction and abrasive, electrolyte, and ultrasonic waves.

\subsubsection{Nondestructive testing and life assessment technology}

The inside, surface, and near surface of pipes before remanufacturing are detected through optical, electrical, sonic, magnetic techniques without destroying the material integrity. Life expectancy estimation and evaluation are conducted on the remanufactured pipes. The five most commonly used nondestructive testing techniques in pipe remanufacturing quality control are ultrasonic, radiographic, eddy current, magnetic particle, and penetrant testing technologies.

\subsubsection{Surface engineering technology}

Surface engineering technology is the key link in remanufacturing. Through different types of surface engineering technology and materials processing technology, the size and performance of damaged and failure parts improves and meets the service demands. The remanufacturing model that China independently creates is based on advanced surface engineering of "size restoration" and "performance improving" approaches. These technologies return the failure parts to the original size. The quality and performance are assured to be better than the prototype product, greatly reducing the production cost and meeting the requirements of energy conservation and emission reduction. According to the failure form, surface engineering technologies such as damage degree and service performance requirements, nano-composite electro-brush plating, thermal spraying, centrifugal self-propagating, and nano-coating are applied in remanufacturing of oil and gas pipelines.

\subsection{Benefit analysis of remanufacturing of oil and gas pipelines}

\subsubsection{Economic benefits}

(1) Direct Economic Benefits

According to statistics, a new oil pipe containing anticorrosion costs 120 yuan per meter, whereas it only costs 69 yuan for 


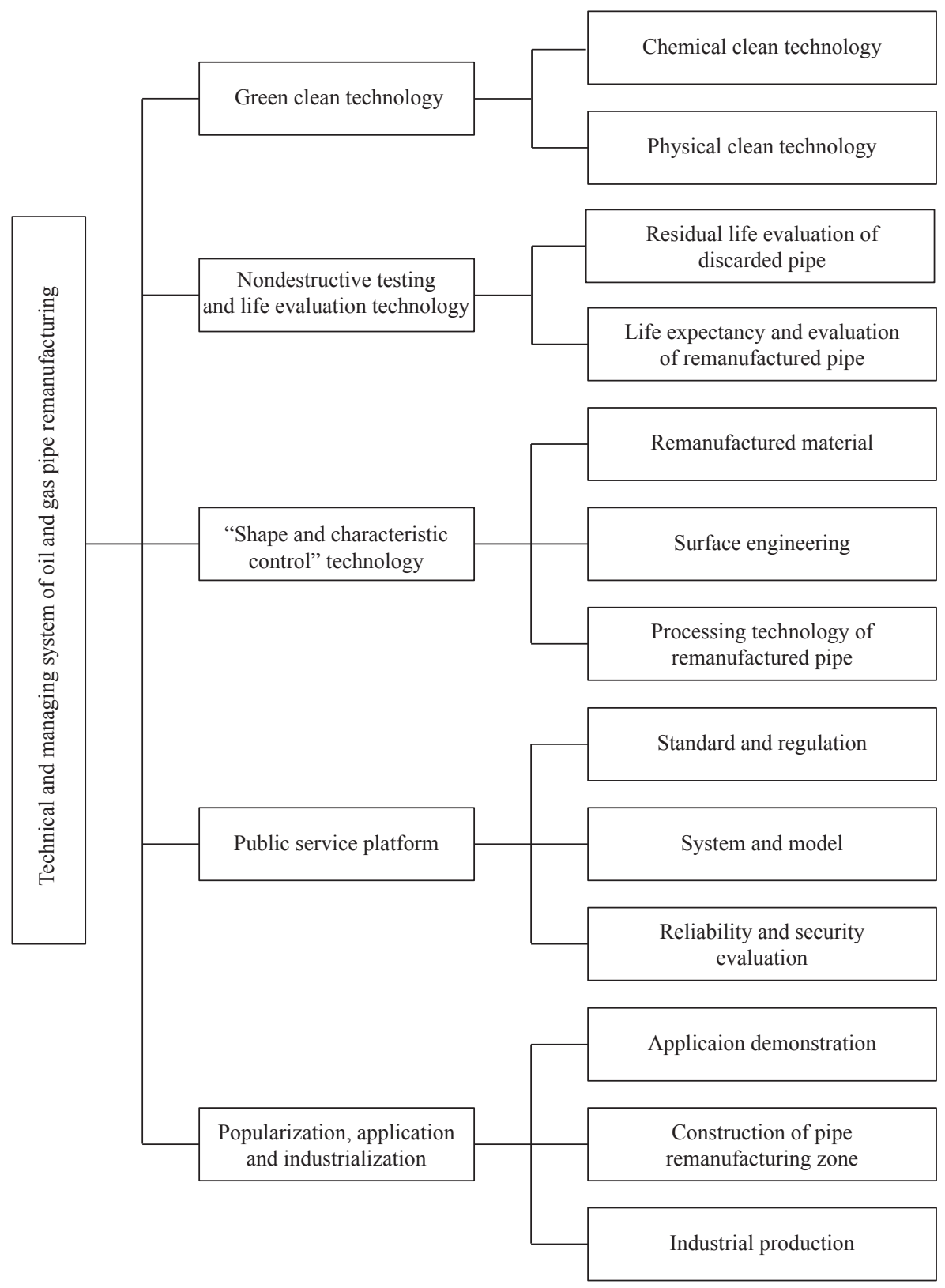

Fig. 2. Technical and management system of oil and gas pipe remanufacturing in China.

remanufacturing the waste oil pipes into metal ceramic composite oil pipes. It indicates that 51 yuan can be saved per meter. If $5 \times 10^{5} \mathrm{t}$ (about $5.5 \times 10^{7} \mathrm{~m}$ ) discarded oil pipes are remanufactured, an investment of about 2.805 billion yuan can be saved [4]. According to the $10 \%$ subsidy policy, 400 million yuan can be saved in total. For remanufacturing enterprises, remanufacturing $5 \times 10^{5} \mathrm{t}$ waste pipes creates an output value of 4 billion yuan, with a rate payment of 500 million yuan.

(2) Indirect Economic Benefits

About $5 \times 10^{5}$ t remanufacturing oil pipes can be used in 40,000 oil wells. When workover cycle of injection and oil wells are $50 \%$ and $20 \%$ raised, respectively, and once to twice reduced, an indirect investment of 1.2 billion yuan can be cut down.

\subsubsection{Social benefits}

(1) Reducing potential security problems

The safety of oil and gas pipelines directly affects the enterprise production, social economy, and stability, as well as national energy supply security. When the gas pipeline is nonfunctional, it causes huge economic losses and damages the environment, causing casualties and other major accidents [5]. Remanufacturing restores the size of discarded pipes and improves the performance. The anticorrosion property is five times equivalent to the prototype and the wear-resisting performance is three times higher. The fouling resistance is two times equivalent to the new product, which greatly improves the service performance of metal pipes. 


\section{(2) Increasing employment positions}

Remanufacturing belongs to the labor-intensive industry; recycling, disassembly, detection, surface engineering technology, and mechanical processing and other links during the discarded oil and gas pipe remanufacturing process drive many related industries, solving employment problems. According to statistics, remanufacturing $5 \times 10^{5} \mathrm{t}$ discarded pipes provides $3,000 \mathrm{em}$ ployment positions.

\subsubsection{Environmental benefits}

(1) Materials saving

Remanufacturing is directly using discarded pipes in production. Most materials (approximately $85 \%$ to $95 \%$ ) of the pipe from the first manufacturing, energy (about $85 \%$ ), and native constituent minerals can be conserved. In the meantime, the service life of new pipes is thrice the ordinary ones. By calculation, if $5 \times 10^{5} \mathrm{t}$ discarded pipes are remanufactured, $1.68 \times 10^{6} \mathrm{t}$ of steel can be saved.

(2) Energy saving and emission reducing

As an important form of circular economy, remanufacturing can significantly save energy and reduce greenhouse gas emissions. In contrast to new pipes, $5 \times 10^{5} \mathrm{t}$ remanufactured pipes can save $93 \%$ energy, $1.73 \times 10^{6} \mathrm{t}$ standard coal and $7.56 \times 10^{6} \mathrm{t}$ water, reducing $3.36 \times 10^{6} \mathrm{t} \mathrm{CO}_{2}$ emission.

To summarize, pipeline remanufacturing reduces environmental process for discarded pipes and production for new pipes, thus reducing environmental pollution and increasing employment opportunities. This has significant economic, social, and environmental benefits, providing technical support for efficiency, energy conservation, and emission reduction in the petrochemical industry.

\section{Suggestions for remanufacturing development of China's oil and gas pipelines}

Oil and gas pipe manufacturing is featured by resource and energy saving and environment protection, keeping information technology, nanotechnology, and biological technology as the central task. It uses the value of discarded pipes, alleviates the contradiction between resource shortage and waste, and reduces environmental pollution caused by scrapped tubes. This is the best way of recycling [6]. At present, oil and gas pipe remanufacturing industry in China is still in the initial stage of development. To promote the development of oil and gas pipe remanufacturing industry in a more scientific and reasonable way, we suggest the following.

\subsection{Concept popularization and recognition improving of pipeline remanufacturing}

In China, oil and gas pipe manufacturing is in its infancy; thus, very few enterprises are aware about pipe remanufacturing. Not to mention the application. Performing various methods to improve the cognition of tubing remanufacturing and actively promoting the use of remanufacturing product is essential. More reports about energy saving and emission reduction effects of pipe remanufacturing are needed. The brand recognition of pipeline remanufacturing should be improved.

\subsection{Setting up a "Government-Industry-University-Research- Utilization" collaborative innovation system of oil and gas pipe remanufacturing}

Guided by the government, universites and research institutes are the main support, enterprise technology is the innovator. Deep fusion of the "Government-Industry-UniversityResearch-Utilization" model and synergy between all types of innovative are needed. Collaborative innovation of oil and gas pipe remanufacturing industry in China needs promotion.

\subsection{Improving the standards and legal system of oil and gas pipe manufacturing}

Actively promoting the establishment of a standards, such as tubing remanufacturing quality, technology, and management is essential. Focusing on the normative operation of design, recycling, disassembly, cleaning, testing, manufacturing processing, and inspection of discarded pipes, standard system and regulations of the oil and gas pipe system in China requires more integration.

\subsection{Actively promoting an independent innovation model of pipe remanufacturing industry}

oil and gas pipe manufacturing industry should be combined with its own specialty and guided by the whole lifecycle theory. Based on the "size recovery and performance promotion" surface engineering technology, combined with the "Industry-University-Research" model. Efforts should be intensified to promote circular and economic model of remanufacturing industry. Efficient dismantling, green cleaning, nondestructive testing and evaluation, advanced surface engineering technology, and other green and efficient key remanufacturing technologies in the application of remanufacturing industry should be developed to ensure the quality of pipe remanufacturing. Combined with the "Internet + " technologies, reverse logistics management and evaluation platform should be established. With links to forward logistics, information flow should be used to guide the control flow, equipment flow, material flow, and personnel flow. Centered on the lifecycle theory, pipe remanufacturing service system should be built for promoting the national development of circular economy. 


\subsection{Strengthening the oil and gas pipe remanufacturing product certification}

Oil and gas pipe remanufacturing certification work can raise the recognition in the consumers' mind, especially of reliability, security, etc. To make the oil and gas pipe remanufacturing development a better environment, certification about the quality of the remanufacturing should be built, along with recognition of the remanufacturing enterprise qualification and remanufacturing enterprise management system. Authentication of oil and gas pipe remanufacturing product certification catalog should be established.

\subsection{Centering on the "one belt and one road" strategy to drive oil and gas pipe remanufacturing industry to "go out"}

As the continuous propulsion of the national strategy "One Belt and One Road," the drilling of most basic oil and gas resources in the main resource countries represented by Russia, Kazakhstan, Turkmenistan, Azerbaijan, Iran, and Saudi Arabia is completed. Finding large oil fields is very challenging, and the exploitation cost is increasing. Moreover, most oil fields have stepped into the later period, accompanied by problems of maintenance, scrap, and other issues. This provides opportunities for the oil and gas pipe remanufacturing industry in China to the world. This will reap huge economic benefits to China and promote core competitiveness of the oil and gas industry in China.

\section{Acknowledgments}

The research on development strategies for the remanufacturing of China's oil and gas pipelines lasted for one year. The authors acknowledge the support and guidance from the Management Department of Chinese Academy of Engineering (CAE); academicians Yupu Wang, Helin Li, Qingtang Yuan, and Wenrui $\mathrm{Hu}$; the Exploration and Development Research Institute of China National Petroleum Corporation (CNPC), Ningxia Petroleum Equipment Remanufacturing Co. Ltd, and other related entities and individuals.

\section{References}

[1] Yu Y. Remanufacturing gives new life of the waste oil pipeInterview with Chinese Academy of Engineering Xu Binshi [J]. China Petrochem, 2014(15):12-16. Chinese.

[2] Xu B S. Theory and technology of equipment remanufacturing engineering [M]. Beijing: National Defence Industry Press, 2007. Chinese.

[3] Xu B S. Remanufacture and recycling economy [M]. Beijing: China Science Publishing \& Media Ltd., 2007. Chinese.

[4] Wu C. A new industrial investigation on technology innovation and development potential of waste oil pipe remanufacturing in China [N]. Oil Daily, 2017-06-27(1). Chinese.

[5] Sun H R. Enlightenment from foreign oil and gas pipeline safety protection [J]. Management \& Technology of SME, 2015(11): 129 Chinese.

[6] Zheng T Y. Remanufacturing gives circular economy a new outlook [N]. Science Review, 2015-08-14(3). Chinese. 